\title{
Linking Space and Nature Syntaxes: the Influence of a Natural View through observed behaviour at Arcosanti, Arizona, USA
}

\author{
Karen Munro \\ Department of Architecture \\ University of Strathclyde, 75 Montrose Street, Glasgow, Scotland, G4 0NG \\ Email: karen.munro@strath.ac.uk \\ Dr David Grierson \\ Department of Architecture \\ University of Strathclyde, 75 Montrose Street, Glasgow, Scotland, G4 0NG \\ Email: d.grierson@strath.ac.uk
}

Keywords Biophilia; environmental psychology; Space Syntax; urbanisation; wilderness; design

\begin{abstract}
The world's urban population is rapidly growing, now exceeding its rural population, and is expected to reach $70 \%$ of the world's total by 2050 . Research in environmental psychology increasingly supports the Biophilia Hypothesis which holds that our connection with Nature is innate. Thus, how do we maintain a human connection to Nature in an increasingly urbanising world? The research explores the boundary between built and natural environments, specifically how proximity, initially through visual connections, to Nature affects how people use social spaces. Case study work is being undertaken at Arcosanti urban laboratory in the Arizona desert. Through development of a Space/Nature Syntax methodology applied within a uniquely compact urban form, this research attempts to understand how maintaining an instinctive bond with Nature can enhance social interactions and inform future design choices within built environments. Initial results support relationships of varying strengths between spatial connectivity, visibility of Nature, and types of social interactions. This paper explores the potential of the cross-disciplinary Space/Nature Syntax methodology as a design and analysis tool, projecting where social interactions within a built space could be influenced by visibility of Nature; where informed design can allow for the essential human/Nature connection to thrive.
\end{abstract}

Introduction In 1984, E.O. Wilson proposed the Biophilia Hypothesis, a theory which presented a relationship with the natural environment as an innate need within humanity. His theory proposed that humanity's connection with Nature was essential, had evolved throughout our development to be beneficial, mentally and physically, and that the relatively recent but increasingly prominent shift from rural living to urban living was detrimental to humanity's collective well-being. (Grinde and Patil, 2009)

Indeed, Wilson was not the first person to recognise the endurance and strength of humanity's appreciation of Nature. Romanticism saw writers such as Henry David Thoreau, Lord Byron, and Ralph Waldo Emerson recognise the importance of Nature as cities grew due to the Industrial Revolution, long before Wilson's 1984 Hypothesis. In 1854's "Walden", Thoreau wrote: "There are moments when all anxiety and stated toil are becalmed in the infinite leisure and repose of nature", while Leo Tolstoy is often quoted as saying "One of the first conditions of happiness is that the link between Man and Nature shall not be broken." Recently, this connection between humans and Nature has become a significant field of scientific study as researchers seek to further explore and explain this undeniable 
bond. A number of studies in environmental psychology have shown spending time in Nature can have physiological and psychological benefits including relieving stress, and alleviating diagnosed psychological disorders. (Berman et al., 2008, Berman et al., 2012, Ward Thompson, 2011, Wilson, 1984, Keniger et al., 2013, Logan and Selhub, 2012, Cervinka et al., 2012, MacKerron and Mourato, 2013, Gehl et al., 2006).

Wilson, Thoreau, and Tolstoy shared an opinion that scientific study has arguably now proven; that a human-Nature connection is vital, beneficial and innate. There are genuine opportunities for a human-Nature link to benefit a modern world therefore this link should be nurtured. However, as the global demographical transition from rural population to urban population shows no signs of slowing, an increasing portion of the world's population has lost or faces losing this connection with the natural environment; the world's global urban population already exceeds $50 \%$ and this is due to increase to $70 \%$ by 2050 (W.H.O., 2012). Living in urban areas has been linked to so many of the problems that it has previously been shown that Nature assists; stress, depression, mood disorders and anxiety (Srivastava, 2009, Sengupta and Benjamin, 2015, Benedictus, 2014, Adli, 2011). As populations shift and cities grow, it becomes increasingly difficult to connect people with true Nature, or wilderness. However, there is scientific support that even minor interventions of Nature into our built environments can be beneficial. A study focussed in health care architecture discovered that a view of a natural environment reduced surgery recovery times (Raanaas $e t$ al., 2012); while other studies have focussed on the benefits of introducing natural elements such as office plants to internal spaces (Brown and Bell, 2007). There is, therefore, both a need and an opportunity for architects and planners to understand how they can design buildings and public spaces which nourish humanity's seemingly biological need for proximity to Nature.

\section{Arcology and Arcosanti}

Arcology - ARChitecture + ecOLOGY - is a concept developed by architect Paolo Soleri (1919 - 2013), as the antithesis to the development of most modern US cities, where reliance on vehicular transport generates massive urban sprawl and decentralisation away from the city centre to never ending suburbs. Soleri stated that these suburbs not only obliterated the ecology of the land they spread over, but that they also obliterated human connections and the ability for personal and collective growth. Where Wilson believed separation from Nature was detrimental to human development, Soleri believed separation from each other to be damaging to humankind. He proposed an alternative to this kind of living: an arcology would be a compact city, bringing people and services back to a centralised location, while the city would be tightly restricted in terms of horizontal growth thus leaving the surrounding natural environment untouched and in a state of wilderness. (Soleri, 1969, Soleri et al., 2011) In addition to providing a model for energy and resource efficiency, Soleri emphasised the potential for arcologies to provide an alternative model of urban living, existing on the boundary between built and natural; "The structure of the habitat is intentionally putting nature at our fingertips" (Soleri, 1993); a point expanded upon by Grierson; "the drawing together of diverse city functions into mixed use, self-contained arcologies would encourage cultural intensification and social integration within their boundaries, while freeing up the surrounding hinterland to remain natural." (Grierson, 2003) In 1970, Soleri and a group of his students formed the Cosanti Foundation and began construction of Arcosanti, a new city presented as an "urban laboratory" and prototype arcology located in the high Sonoran desert of Arizona, USA. Arcosanti aims to explore high density, mixed use design built on a pedestrian scale, while leaving hundreds of acres of surrounding land as natural environment, 
allowing its residents to be both "city and country dwellers" (Soleri, 1993); Fig.1 shows a panorama of the Arcosanti site, and some of the social spaces within. At Arcosanti, the "punch" between city and natural is immediate, not gradual or tempered as in traditional urban environments (Soleri, 1993); a person can be in untouched natural environment moments after leaving the density of the city. Soleri devoted his attention to the technological, architectural and infrastructural elements of an Arcology, and he repeatedly stated that he could not, and would not, predict the social dynamic: "What the project wants to avoid is planning the lives of its residents. They are offered a specific grid of environmental resources (the instrument) within which to act and play out their lives (the music).” (Soleri, 1993)
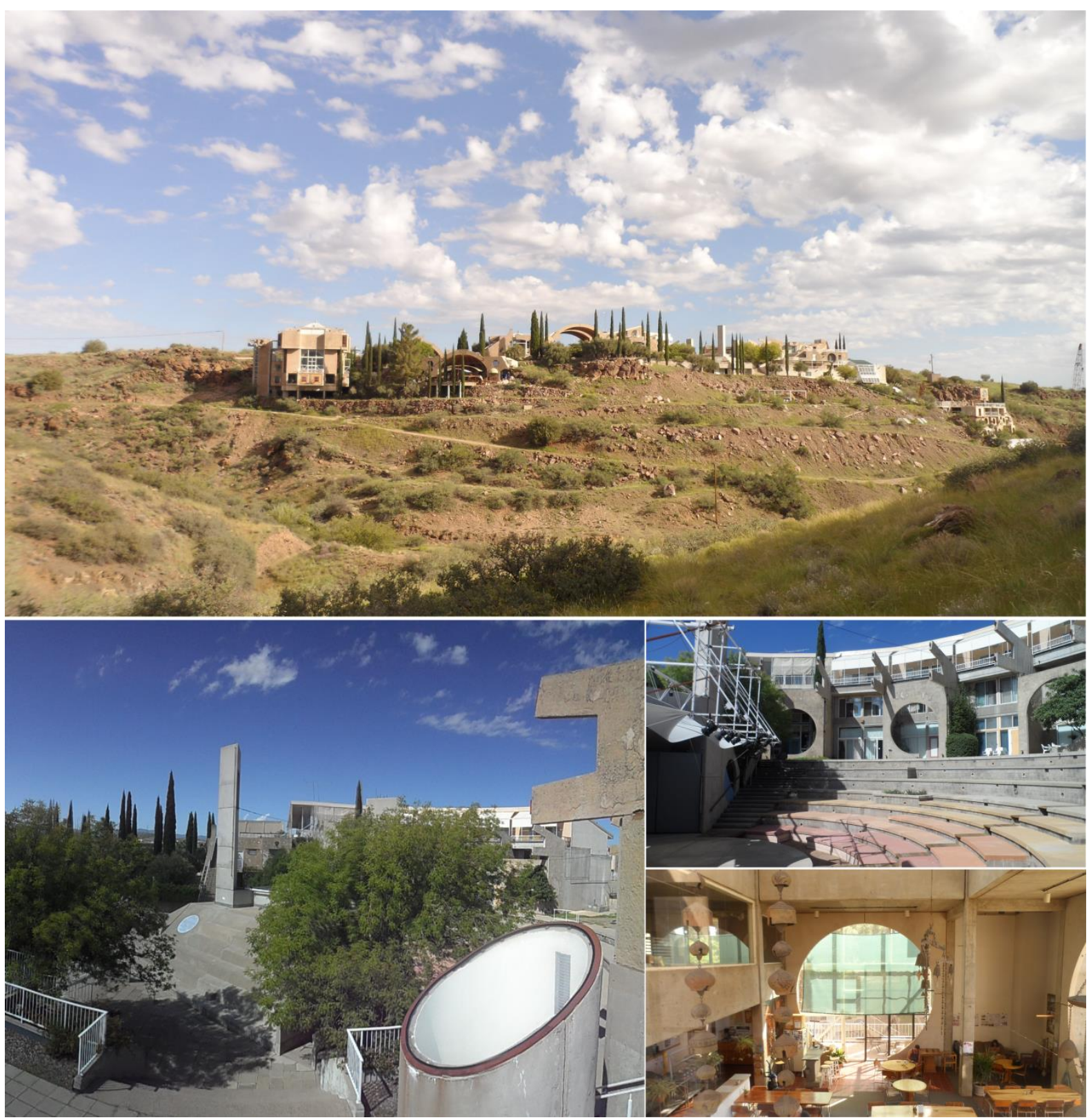

Figure 1 Images of Arcosanti (all taken by Karen Munro)

Soleri believed that the social identity of an arcology would and should develop naturally, and the continued construction of Arcosanti now gives an opportunity for the social outcomes to be investigated. This work particularly focusses on the effect the unique proximity to the natural environment, namely through a visual connection, has on the social interactions 
observed at Arcosanti. Writings in Romanticism describe time in Nature as peaceful, calming, introspective; can it be witnessed at Arcosanti, then, that a strong visual connection with Nature creates spaces which promote privacy and solitude? Or is it observed that the most visually connected to Nature spaces are the most appealing for group social events, a place to gather and enjoy together? It has been suggested that the prevalence of mental illness seen in cities is a result of social stress and social isolation (Benedictus, 2014), therefore understanding the social influence of a view of Nature from within a built environment has clear applicable benefits. The research work on which this paper is based has developed a methodology to quantify a built space's visual relationship to the natural environment, which has been used alongside Space Syntax analysis and Behavioural Observations in social spaces at Arcosanti to determine whether a visual connection to the natural environment has a significant effect on social interactions, comparative to spatial connectivity. The paper will briefly describe the development of this Space/Nature Syntax methodology, before summarising the findings of its application on 15 social spaces at Arcosanti, and how it could be used to inform future design at both Arcosanti and further afield.

Development of Method For the purpose of this study, a space is classed as a social space and analysed in the research if it is an interior or exterior space available for use by Arcosanti residents at any time of the day or night. There were 15 such spaces identified which were then analysed according to the methodology to be described. A full description of the development of the Space/Nature Syntax methodology has been accepted for publication in Open House International, Vol. 41, No.4, in December 2016. (Munro and Grierson, 2016)

\section{Space Syntax}

Space Syntax is a theory developed by Bill Hiller and Julienne Hanson for analysing spatial configurations and giving statistical value to spaces within buildings and cities, facilitating analysis and planning (Hillier et al., 1976, Hillier and Hanson, 1984, Hillier, 1999, Hillier, 2007, Jeong and Ban, 2011) Space Syntax is used to determine areas within individual buildings or the wider urban environment which have the potential for high social interaction (Campos and Fong, 2003) and has therefore been used in this study to analyse the social spaces at Arcosanti to determine which, at least according to spatial analysis, should be the most and least dynamic.

A brief description of the terms and equations associated with Space Syntax which will be used in this paper are as follows:

- $\mathrm{N}=$ the number of spaces in a System (Arcosanti)

- Depth (D) - the number of spaces between two spaces. A new Depth is reached when a threshold is crossed.

- Total Depth (TD) - the sum of all spaces at all Depths

- Mean Depth (MD) - the average Depth from the Root Space to all other spaces in the System.

$$
\mathrm{MD}=\mathrm{TD} / \mathrm{N}-1
$$

- Connectivity $(\mathrm{C})$ - a measure of the number of immediate spaces adjoining the Root Space.

$$
\mathrm{C}=1 / \text { No. of spaces at Depth } 1
$$


- Relative Asymmetry (RA) - a measure of Integration for Systems of comparable size; values are between 0 and 1 , where 0 is a strongly integrated space and 1 is a weakly integrated space.

$$
\mathrm{RA}=2(\mathrm{MD}-1) / \mathrm{N}-2
$$

- Real Relative Asymmetry (RRA) - a measure of Integration for Systems of drastically different sizes. As with the RA, the lower the RRA value, the more accessible a space is; 0.4 to 0.6 is considered to indicate strong integration. (Bafna, 2003, Hillier and Hanson, 1984)

$$
\mathrm{RRA}=\mathrm{RA} / \mathrm{D}_{\mathrm{k}}
$$

- Dk - average RA of a System of a particular size

- Integration Value (IV) - the inverse of the RRA; therefore the higher the IV, the more Integrated the space is and more likely to be a lively space.

$$
\mathrm{IV}=1 / \mathrm{RRA}
$$

(Hillier and Hanson, 1984, Klarqvist, 1993, Jeong and Ban, 2011, Bafna, 2003)

\section{Nature Syntax}

The Nature Syntax method is being developed through this research work. Nature Syntax analysis produces a value named the Visibility of Nature (VN) value, which is between 0 and 1 , where 0 is no visual connection to Nature and 1 is complete, $360^{\circ}$ visual connection to Nature. The VN value represents the ratio of the visibility of the natural environment out of the total external visibility from that space and can be calculated by the equation:

$$
\text { Visibility of Nature }(V N)=\frac{(\text { Permeability } x \text { Naturalness of View })}{100}
$$

\section{Permeability}

Permeability in the context of this work refers to the area of façade and ceiling of a space which is either open (e.g. an archway) or transparent (e.g. a window or skylight) - any opening through which the environment external to the space is visible. A Permeability value between 0 and 1 was calculated for each social space, where 0 is a social space which is completely visually enclosed to its external environment, while 1 is a social space which is completely visually open to its external environment.

$$
\text { Permeability }=\frac{\left(\frac{\text { Total Permeable Surface Area }}{\text { Total Surface Area }}\right)}{100}
$$

\section{Naturalness of View}

A land cover site plan of Arcosanti was created which assigned land cover types according to the U.S. Geological Survey Land Cover Institute National Land Cover Database (NLCD) 2006, which documents land cover type according to well defined criteria, covering wide variants in both built and natural land cover (US Department of the Interior and US Geological Survey, 2015, Anderson et al., 1976). There were four categories for "Built" land 
cover, defined by the percentage of coverage which is constructed materials, and one for "Natural", with values from 0 to 1 being assigned to each category. As "Natural" land coverage was the focus of the study, this category was given a value of 1 , with "Developed, High Intensity" receiving a value of 0 , and the intermediate classifications given values in intervals of 0.25 . Fig.2a shows the land cover plan produced when applying these criteria to the current Arcosanti site, while fig. $2 \mathrm{~b}$ shows how each criteria translates to a Naturalness of View value

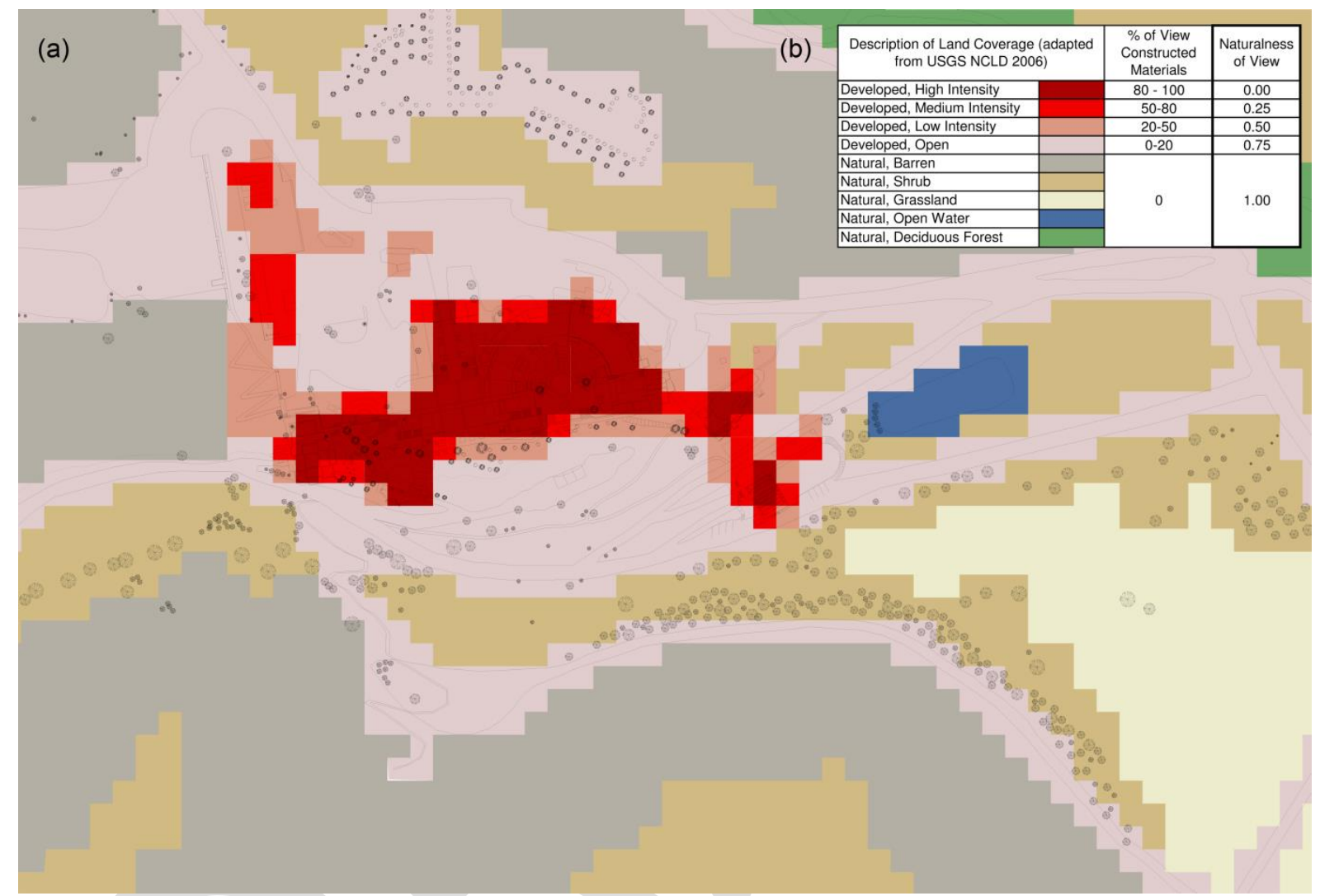

Figure 2 (a) NCLD Phase I Arcosanti Plan and (b) Adapted NCLD Legend

In order to determine the Naturalness of View from each space, field of vision studies were carried out in both plan and section for each of the 15 social spaces. The foveal and peripheral fields of vision (based on (Gehl et al., 2006)) from a centre point in the space were drawn for each direction and overlaid onto the Arcosanti land cover site plan. The type of land cover which was predominantly covered by the foveal vision was taken to be the type of land cover most visible for that direction, and the associated value between 0 and 1 was documented. This process was then repeated in section for each space and direction to take into account the three-dimensionality of both the structures and Arcosanti site, and confirm the results found on plan. Finally, the values documented were confirmed visually at the Arcosanti site by the researcher. The final value for Naturalness of View for each space is the sum of the value for the five directions, divided by 5 .

The Permeability and Naturalness of View figures for each space were then used to find the Visibility of Nature value using the previously stated formula.

\section{Behavioural Observations}


A Behavioural Observation method was developed through background research into the observational methods commonly used in environmental psychology (Thwaites, 2007, Goličnik and Ward Thompson, 2010, Costa, 2011, Gehl, 2011, Gehl, 1987, Gehl, 2010, Liu and Sibley, 2004, Moirongo, 2002, Simpson, 2011, Zhang and Lawson, 2009). A total of 107 observations were carried out on site at Arcosanti over a 3 month period, with the following behaviours being noted:

- Type of Space Use

○ "Active" - space being directly used for an activity; space is the end destination.

○ "Inactive" - space being used inactively; as a through route to elsewhere.

- Level of Planning

○ "Planned" - a predetermined activity taking place at an agreed time e.g. an arranged event; a work task; a meeting; a guided tour group.

○ "Unplanned" - a spontaneous activity undertaken e.g. a social interaction; informal/impromptu meeting; non-essential use as through route.

- Visual Interaction with Natural Environment

- A user observed displaying behaviour which facilitates a visual interaction with environment e.g. looking out window; positioning body towards natural environment; pointing; drawing; photographing.

\section{Correlation Analysis}

Finally, using statistically software MiniTab, correlations were calculated between the results of the Space Syntax, Nature Syntax and Behavioural Observation studies which allowed an initial understanding of where the data is suggesting relationships between the variants.

\section{Limitations}

The methodology which has been introduced is the result of research work drawing together existing methods in a novel way; therefore, as with any research of this kind, there remains areas which could be further developed.

As a methodology which at its core seeks to explore the link between a sensory experience of Nature and social interaction, the research is limited by its focus on solely visual connectivity. This focus was selected as it is the most established in previous senseenvironment studies, however future work should also explore the effects of senses such as sound and smell to fully understand the sensory experience created by proximity to Nature, and the resulting effect on social interactions.

Similar to this, the method in its current format lacks qualitative data on the psychological/emotional effect of proximity to Nature; the quantitative data gathered may suggest links between spatial connectivity, connection to Nature, and social interactions, but only a qualitative study which focussed on the thoughts and feelings of the spaces' users would confirm a cause-and-effect relationship between these factors.

Finally, repeat applications of the methodology at sites other than Arcosanti would enhance the connections found and further develop the Space/Nature Syntax methodology.

Results The research work applied Space/Nature Syntax to 3 stages of construction at Arcosanti in order to display the applicability of the method as both an analysis and design 
tool. The left of fig. 3 shows the Arcosanti site as currently constructed; the right of fig. 3 shows the planned construction for Phase II (blue) and Phase III (orange).

- Phase I - Arcosanti site as currently built; Space Syntax, Nature Syntax and Behavioural Observations were carried out based on existing conditions.

- Phase II - Short term construction; Space Syntax and Nature Syntax was recalculated, to the closest possible accuracy, for the Arcosanti site following the realisation of the Cosanti Foundation's immediate construction goals. This involves the completion of the third floor of an existing building; the construction of one new building; and the installation of a permanent canopy above a currently open social space. It also creates a new social space to be analysed. Using the values for Behaviour observed in Phase I, and the correlations which suggested a statistically significant relationship, Projected Usage figures for each of the existing social spaces were calculated, providing a suggestion of how the completion of the short term construction goals could alter how the existing social spaces would be used

- Phase III - Long term construction; based on a planned phase in Arcosanti's construction named "Critical Mass" which would see the construction of a number of new buildings, of which all except one would be located south of the existing construction, along with an expansive greenhouse system. As with Phase II, the Space Syntax and Nature Syntax process was repeated for each of the existing social spaces, to the closest possible accuracy, before Projected Usages figures were suggested.

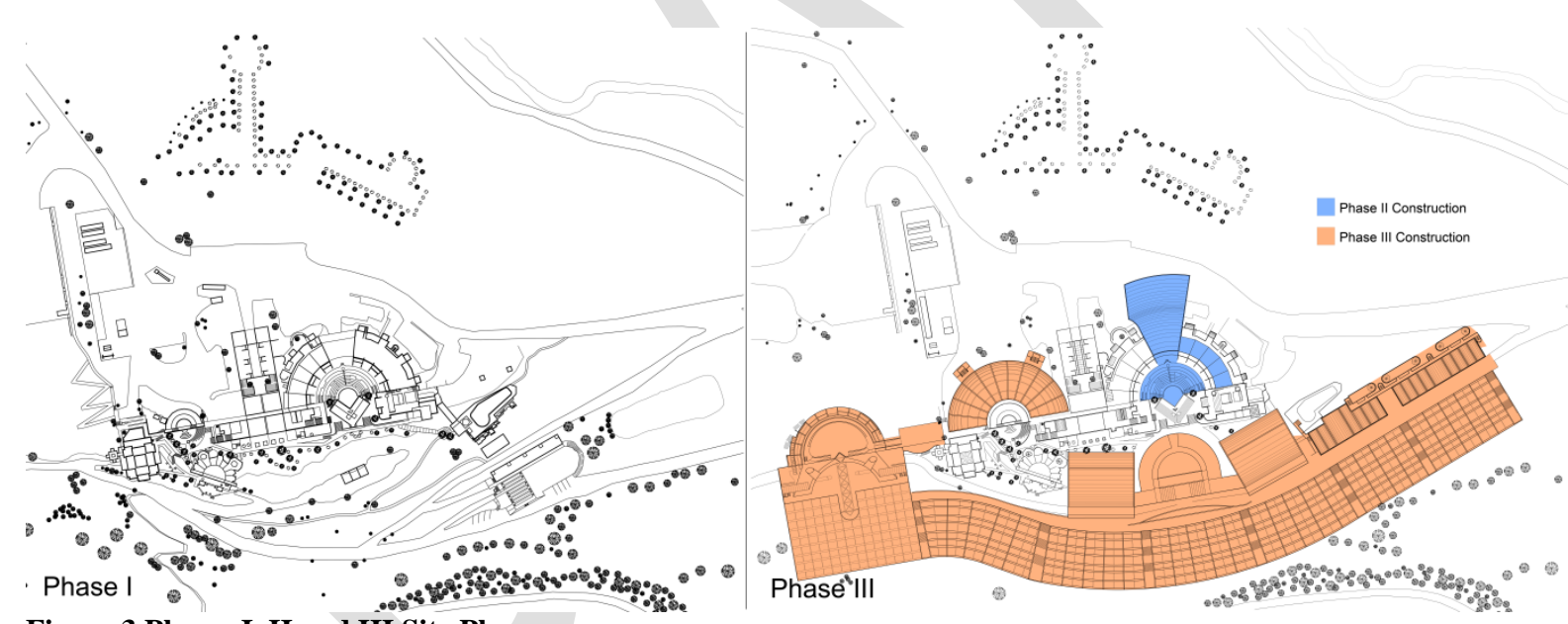

Figure 3 Phases I, II and III Site Plan

The changes to spatial connectivity and visibility of Nature of the existing spaces were possible to calculate with reasonable accuracy as the Cosanti Foundation's construction plans for both Phases II and III were developed enough to allow this. The plans were not, however, detailed enough for any new social spaces to be considered with the exception of the one discussed in Phase II: predominantly as there is little to no available information on the intended function of each new space. Therefore, it is essential to acknowledge that where the construction of a new building may alter the spatial connectivity or visibility of Nature of an existing space, it could certainly do so while providing a new social space with an equivalent spatial or visual connection.

\section{Phase I}


PHASE I

ARCOSANTI SITE AS EXISTING

ORDERED BY LOWEST TO HIGHEST RRA (MOST TO LEAST SPATIALLY CONNECTED)

\begin{tabular}{|l|r|r|r|r|r|r|}
\hline \multicolumn{1}{|c|}{ Social Space } & Total Depth & Mean Depth & Connectivity & RA & RRA & Integration Value \\
\hline & & & & & & \\
\hline Vaults & 1125 & 5.0 & 0.17 & 0.0354 & $\mathbf{0 . 7 5 2 3}$ & 1.3292 \\
\hline Community Room & 1161 & 5.1 & 0.20 & 0.0368 & $\mathbf{0 . 7 8 2 4}$ & 1.2780 \\
\hline Library/Rec Room & 1367 & 6.0 & 0.50 & 0.0449 & $\mathbf{0 . 9 5 4 8}$ & 1.0473 \\
\hline Amphitheatre Seating & 1403 & 6.2 & 0.17 & 0.0463 & $\mathbf{0 . 9 8 5 0}$ & 1.0153 \\
\hline Ceramics & 1519 & 6.7 & 0.33 & 0.0509 & $\mathbf{1 . 0 8 2 0}$ & \\
\hline Sky Theatre & 1522 & 6.7 & 0.50 & 0.0510 & $\mathbf{1 . 0 8 4 5}$ & 0.9242 \\
\hline Vault Roof & 1580 & 7.0 & 0.50 & 0.0533 & $\mathbf{1 . 1 3 3 1}$ & 0.9220 \\
\hline Roof Patio & 1587 & 7.0 & 0.33 & 0.0535 & $\mathbf{1 . 1 3 8 9}$ & 0.8826 \\
\hline Amphitheatre Stage & 1664 & 7.4 & 0.20 & 0.0566 & $\mathbf{1 . 2 0 3 4}$ & 0.8780 \\
\hline Café & 1676 & 7.4 & 0.20 & 0.0570 & $\mathbf{1 . 2 1 3 4}$ & 0.8310 \\
\hline Music Centre & 1684 & 7.5 & 0.33 & 0.0573 & $\mathbf{1 . 2 2 0 1}$ & 0.8241 \\
\hline EC Roof & 1771 & 7.8 & 1.00 & 0.0608 & $\mathbf{1 . 2 9 2 9}$ & 0.8196 \\
\hline Classroom & 1828 & 8.1 & 1.00 & 0.0630 & $\mathbf{1 . 3 4 0 6}$ & 0.7734 \\
\hline Red Room & 2063 & 9.1 & 0.33 & 0.0723 & $\mathbf{1 . 5 3 7 3}$ & 0.7459 \\
\hline Office & 2103 & 9.3 & 0.25 & 0.0738 & $\mathbf{1 . 5 7 0 7}$ & 0.6505 \\
\hline Averages & 1604 & & & & & 0.6366 \\
\hline Phase I RA & & & 0.40 & 0.0542 & $\mathbf{1 . 1 5 2 8}$ & \\
\hline
\end{tabular}

Figure 4 Phase I RRA Results

The table in fig. 4 shows the results of the complete Space Syntax analysis, with the 15 social spaces ordered from lowest to highest RRA; in other words, most to least spatially connected. In Phase I the social space on the Arcosanti site with the lowest RRA, and therefore the highest spatial connectivity, was the Vaults at 0.7523 , while the highest RRA returned and therefore least spatially connected was the Office at 1.5707. Fig. 5 displays the VN values for each social space for Phase I, ordered from highest VN to lowest. The social space with the highest VN value, and thus highest visual connection to Nature, was the East Crescent Roof with a value of 0.69 , while both the Community Room and the Library/Rec Room had VN values of 0 . The initial analysis of Phase I took these 5 spaces, as the extremes of the results, and examined how they were observed being used in the Behavioural studies. Fig.6 shows the results of these observations, in both actual numbers of each activity in each space, and the percentage share of each activity in each space over all observations.

$$
\text { PHASE I }
$$

ARCOSANTI SITE AS EXISTING

ORDERED FROM HIGHEST TO LOWEST VN (MOST TO LEAST VISIBILITY OF NATURE)

\begin{tabular}{|c|c|c|c|c|c|c|c|c|c|c|c|c|c|c|}
\hline \multirow{3}{*}{ Social Space } & \multicolumn{7}{|c|}{ Permeability (\%) } & \multirow{2}{*}{\multicolumn{6}{|c|}{ Naturalness of View }} & \multirow{3}{*}{$\begin{array}{l}\text { Visibility of Nature } \\
\text { (VN) Value }\end{array}$} \\
\hline & \multirow{2}{*}{$\begin{array}{c}\mathrm{N} \\
\text { Open }\end{array}$} & \multirow{2}{*}{$\begin{array}{c}\mathrm{E} \\
\text { Open }\end{array}$} & \multirow{2}{*}{\begin{tabular}{|c|} 
S \\
Open
\end{tabular}} & \multirow{2}{*}{$\begin{array}{c}\text { W } \\
\text { Open }\end{array}$} & \multirow{2}{*}{\begin{tabular}{|c|} 
ABOVE \\
Open \\
\end{tabular}} & \multirow{2}{*}{$\begin{array}{l}\text { Total } \\
\text { Open }\end{array}$} & \multirow{2}{*}{ Ratio } & & & & & & & \\
\hline & & & & & & & & $\mathrm{N}$ & $E$ & $\mathrm{~S}$ & W & ABOVE & $\mathrm{T}$ & \\
\hline East Crescent Roof & 91 & 87 & 90 & 90 & 100 & 91.6 & 0.92 & 0.75 & 1 & 1 & 0 & 1 & 0.75 & 0.69 \\
\hline Vault Roof & 100 & 100 & 100 & 100 & 100 & 100 & 1.00 & 0.5 & 0 & 1 & 0 & 1 & \begin{tabular}{|l|}
0.5 \\
\end{tabular} & 0.50 \\
\hline Sky Theatre & 82 & 100 & 100 & 100 & 100 & 96.4 & 0.96 & 0 & 0 & 1 & 0 & 1 & 0.4 & 0.39 \\
\hline Roof Patio & 95 & 82 & 91 & 90 & 100 & 91.6 & 0.92 & 0.5 & 0 & 0 & 0 & 1 & 0.3 & 0.27 \\
\hline Amphitheatre Seating & 100 & 100 & 100 & 100 & 100 & 100 & 1.00 & 0 & 0 & 0 & 0 & 1 & 0.2 & 0.20 \\
\hline Ceramics & 12 & 65 & 100 & 65 & 74 & 63.2 & 0.63 & 0 & 0 & 0.25 & 0 & 1 & 0.25 & 0.16 \\
\hline Vaults & 42 & 30 & 100 & 33 & 32 & 47.4 & 0.47 & 0 & 0 & 0.5 & 0 & 1 & 0.3 & 0.14 \\
\hline Café & 0 & 25 & 27 & 33 & 16 & 20.2 & 0.20 & 0 & 0.25 & 0.75 & 0.75 & 1 & 0.55 & 0.11 \\
\hline Amphitheatre Stage & 100 & 46 & 42 & 43 & 38 & 53.8 & 0.54 & 0 & 0 & 0 & 0 & 1 & 0.2 & 0.11 \\
\hline Red Room & 15 & 19 & 28 & 12 & 6 & 16 & 0.16 & 0.5 & 0.5 & 0.75 & 0 & 0.5 & 0.45 & 0.07 \\
\hline Office & 0 & 33 & 26 & 0 & 9 & 13.6 & 0.14 & 0 & 0.5 & 0.75 & 0 & 1 & 0.45 & 0.06 \\
\hline Music Centre & 53 & 0 & 64 & 0 & 0 & 23.4 & 0.23 & 0 & 0 & 0.75 & 0 & 0 & 0.15 & 0.04 \\
\hline Classroom & 0 & 30 & 0 & 29 & 0 & 11.8 & 0.12 & 0 & 0.75 & 0 & 0 & 0 & 0.15 & 0.02 \\
\hline Community Room & 0 & 54 & 0 & 0 & 0 & 10.8 & 0.11 & 0 & 0 & 0 & 0 & 0 & 0 & 0.00 \\
\hline Library/Rec Room & 0 & 0 & 0 & 0 & 0 & 0 & 0.00 & 0 & 0 & 0 & 0 & 0 & 0 & 0.00 \\
\hline AVG & 46 & 51 & 58 & 46 & 45 & 49.3 & 0.49 & 0.2 & 0.2 & 0.5 & 0.1 & 0.7 & 0.31 & 0.18 \\
\hline
\end{tabular}

Figure 5 Phase I VN Results 
As expected, the East Crescent Roof was the social space where most people were observed displaying a Visual Interaction with the Natural Environment, with $84 \%$ of all such interaction observed occurring in this space. The Community Room and Library/Rec Room both had 0\% of Visual Interaction with Natural Environment, again expected as they have no visual relationship to Nature. The East Crescent Roof was observed to have been generally used more regularly than the Community Room and Library/Rec Room, with $18.7 \%$ of Total People over all observations, compared to $8.1 \%$ and $0.8 \%$.

An interesting outcome from the observational data is that the East Crescent Roof experienced a contrasting type of social interactions from both the Community Room and the Library/Rec Room. The East Crescent Roof saw $23.7 \%$ of total Active use but $0 \%$ of Inactive, compared to the Community Room which only saw $4.8 \%$ of Active Use, but $20.1 \%$ of Inactive use. These differences were less significant for the Library/Rec Room, but were still greater for Inactive (1.6\%) than Active (0.6\%). Additionally, the East Crescent Roof was the location for a higher percentage of all Planned Use at $22.8 \%$ when compared to Unplanned Use at 2.8\%, again contrasting with the Community Room which had only $4.8 \%$ of Planned Use, but $20.6 \%$ of Unplanned Use, and the Library/Rec Room which saw $0 \%$ of Planned Use but $3.9 \%$ of Unplanned Use. This would seem to suggest that a space which has a high visual connection to Nature is more likely to see Active, Planned use, while a low visual connection to Nature promotes Inactive, Unplanned use.

BEHAVIOURAL OBSERVATIONS, AS CARRIED OUT ON SITE AT ARCOSANTI ORDERED ALPHABETICALLY
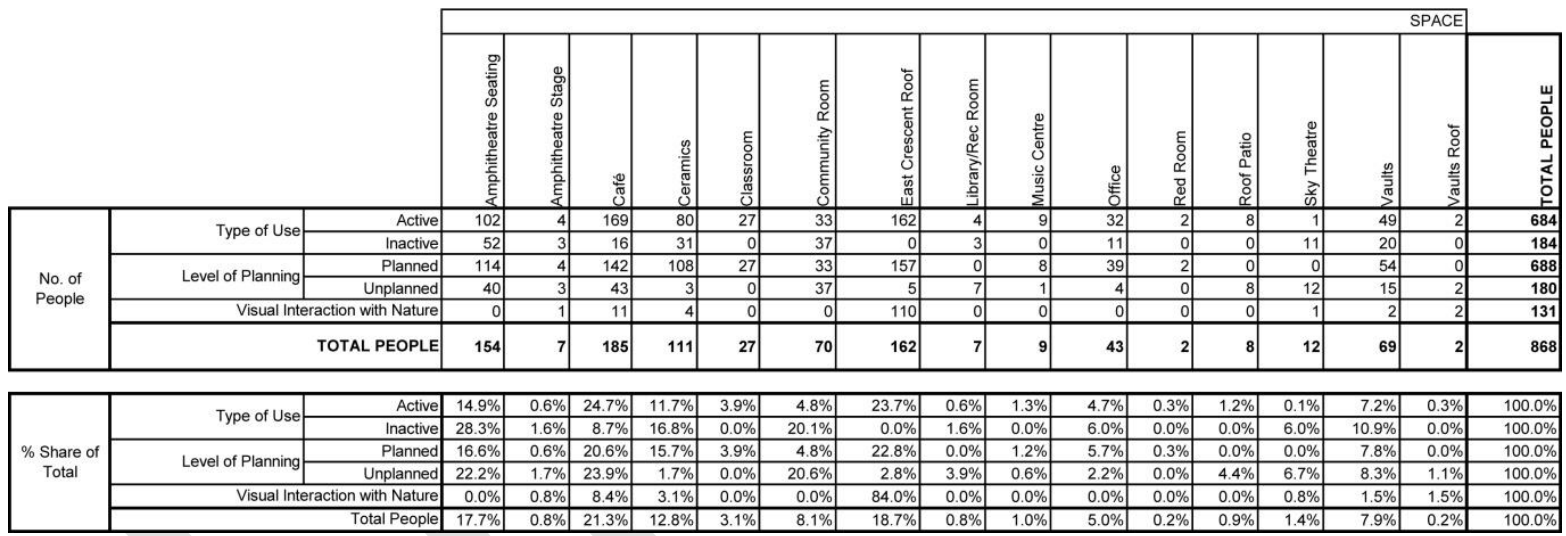

Figure 6 Phase I Behavioural Observation Results

The Behavioural Observations show that the differences in activity between the Vaults and the Office, the most and least spatially connected spaces, were not hugely significant when compared with the differences for the highest and lowest values of the VN value; the Vaults had a 7.9\% share of Total People, while the Office's share was 5\%. These slight differences are consistent throughout all categories of activity observed in the Observation studies. The Vaults has only marginally more a percentage of Total Active Use than the Office $(7.2 \%$ compared with 4.7\%); Total Inactive Use (10.9\% to 6\%); Planned Use (7.8\% to 5.7\%); and Unplanned Use (8.3\% to $2.2 \%)$. 


\begin{tabular}{|c|c|c|c|c|c|c|c|c|c|}
\hline RRA & & & & & & \multicolumn{4}{|c|}{ Statistically significant positive correlation } \\
\hline $\begin{array}{c}r=-0.969 \\
p=0.00\end{array}$ & IV & & & & & \multicolumn{4}{|c|}{ Statistically significant negative correlation } \\
\hline $\begin{array}{l}r=0.301 \\
p=0.276\end{array}$ & $\begin{array}{l}r=-0.354 \\
p=0.195\end{array}$ & C & & & \multicolumn{5}{|c|}{$\begin{array}{l}r=\text { Pearson's correlation, where } 1 /-1 \text { is a perfect positive/negative correlation, } \\
\text { and } 0 \text { is no correlation }\end{array}$} \\
\hline $\begin{array}{l}r=0.040 \\
p=0.887\end{array}$ & $\begin{array}{l}r=-0.130 \\
p=0.644\end{array}$ & $\begin{array}{l}r=0.454 \\
p=0.090\end{array}$ & VN & & \multicolumn{5}{|c|}{$\begin{array}{l}p=P \text {-value, an indicator of probability of correlation occurring by chance, } \\
\text { where }<0.1 \text { a statistically significant correlation (less than } 10 \% \text { probability of } \\
\text { chance) }\end{array}$} \\
\hline $\begin{array}{l}r=-0.146 \\
p=0.604\end{array}$ & $\begin{array}{l}r=0.125 \\
p=0.657\end{array}$ & $\begin{array}{l}r=-0.020 \\
p=0.942\end{array}$ & $\begin{array}{l}r=0.235 \\
p=0.398\end{array}$ & $\begin{array}{l}\text { TOTAL } \\
\text { PEOPLE }\end{array}$ & & & & & \\
\hline $\begin{array}{l}r=-0.014 \\
p=0.960\end{array}$ & $\begin{array}{l}r=-0.015 \\
p=0.957\end{array}$ & $\begin{array}{l}r=0.118 \\
p=0.675\end{array}$ & $\begin{array}{l}r=0.321 \\
p=0.244\end{array}$ & $\begin{array}{l}r=0.972 \\
p=0.000\end{array}$ & ACTIVE USE & & & & \\
\hline $\begin{array}{l}r=-0.532 \\
p=0.041\end{array}$ & $\begin{array}{l}r=0.553 \\
p=0.032\end{array}$ & $\begin{array}{l}r=-0.498 \\
p=0.059\end{array}$ & $\begin{array}{c}r=-0.190 \\
p=0.498\end{array}$ & $\begin{array}{l}r=0.568 \\
p=0.027\end{array}$ & $\begin{array}{l}r=0.360 \\
p=0.187\end{array}$ & $\begin{array}{l}\text { INACTIVE } \\
\text { USE }\end{array}$ & & & \\
\hline $\begin{array}{l}r=-0.039 \\
p=0.891\end{array}$ & $\begin{array}{l}r=0.014 \\
p=0.959\end{array}$ & $\begin{array}{l}r=0.098 \\
p=0.727\end{array}$ & $\begin{array}{l}r=0.309 \\
p=0.262\end{array}$ & $\begin{array}{l}r=0.979 \\
p=0.000\end{array}$ & $\begin{array}{l}r=0.980 \\
p=0.000\end{array}$ & $\begin{array}{l}r=0.458 \\
p=0.086\end{array}$ & $\begin{array}{c}\text { PLANNED } \\
\text { USE }\end{array}$ & & \\
\hline $\begin{array}{l}r=-0.481 \\
p=0.069\end{array}$ & $\begin{array}{l}r=0.482 \\
p=0.069\end{array}$ & $\begin{array}{l}r=-0.454 \\
p=0.089\end{array}$ & $\begin{array}{c}r=-0.139 \\
p=0.621\end{array}$ & $\begin{array}{l}r=0.650 \\
p=0.009\end{array}$ & $\begin{array}{l}r=0.528 \\
p=0.043\end{array}$ & $\begin{array}{l}r=0.735 \\
p=0.002\end{array}$ & $\begin{array}{l}r=0.481 \\
p=0.070\end{array}$ & $\begin{array}{l}\text { UNPLANNED } \\
\text { USE }\end{array}$ & \\
\hline $\begin{array}{l}r=0.162 \\
p=0.563\end{array}$ & $\begin{array}{c}r=-0.184 \\
p=0.512\end{array}$ & $\begin{array}{l}r=0.592 \\
p=0.020\end{array}$ & $\begin{array}{l}r=0.701 \\
p=0.004\end{array}$ & $\begin{array}{l}r=0.504 \\
p=0.056\end{array}$ & $\begin{array}{l}r=0.626 \\
p=0.012\end{array}$ & $\begin{array}{l}r=-0.196 \\
p=0.485\end{array}$ & $\begin{array}{c}r=-0.082 \\
p=0.772\end{array}$ & $\begin{array}{l}r=0.605 \\
p=0.017\end{array}$ & $\begin{array}{l}\text { VIS. INT. } \\
\text { WITH } \\
\text { NATURE }\end{array}$ \\
\hline
\end{tabular}

Figure 7 Phase I Correlation Matrix

The discussions of individual spaces suggests a relationship between visibility of a natural environment and social interactions and also suggest that, at Arcosanti, the spatial integration of a space does not influence its social interactions as much as one might expect. The spaces which result at extremes of the Space Syntax analysis do not have as significant a distinction in any type of social interaction as those which are at the extremes of the Nature Syntax results, suggesting that the visibility of Nature from a social space has a more significant influence on the social interaction within that space. While this chapter discusses only 5 of 15 spaces, these initial findings seem to be somewhat supported by the correlations produced for all Observations in the study. Fig. 7 shows statistically significant correlations established, including those between RRA value, and Inactive Use and Unplanned Use, supporting the patterns seen in the discussion. The discussion also suggested relationships between VN value and Active Use and Planned Use, but these correlate less significantly than the discussion of individual spaces implied. Overall, the discussion of individual spaces and the correlation data seems to support the finding that the RRA is influential in determining different type of social interaction, but the $\mathrm{VN}$ value's influence needs further clarification.

Application This section will demonstrate how the methodology outlined in the previous section can be used to calculate how future construction at the Arcosanti site would alter RRA and VN values, and how these altered values in turn could influence changes in the social interactions experienced in each of the existing social spaces.

\section{Calculated Changes in RRA and VN}

In Phase II the East Crescent Roof would be constructed on, with new studio apartments replacing the existing social space. The empty "keystone" lot adjacent to the East Crescent Roof would have an indoor theatre constructed, which would create a number of new spaces 
including a new social space, which has been named the Keystone Courtyard and has been included in the Phase II analysis. The Keystone Theatre also removes a potential route across the Arcosanti site.

PHASE II

SHORT TERM CONSTRUCTION

ORDERED BY LOWEST TO HIGHEST RRA (MOST TO LEAST SPATIALLY CONNECTED)

\begin{tabular}{|l|r|r|r|r|r|r|}
\hline \multicolumn{1}{|c|}{ Social Space } & Total Depth & Mean Depth & Connectivity & RA & RRA & Integration Value \\
\hline & & & & & & \\
\hline Vaults & 1276 & 5.2 & 0.17 & 0.0345 & $\mathbf{0 . 7 8 3 9}$ & 1.2756 \\
\hline Community Room & 1293 & 5.3 & 0.20 & 0.0351 & $\mathbf{0 . 7 9 6 9}$ & 1.2549 \\
\hline Keystone Courtyard* & 1528 & 6.2 & 0.50 & 0.0429 & 0.9755 & 1.0251 \\
\hline Library/Rec Room $^{*}$ & 1550 & 6.3 & 0.50 & 0.0437 & $\mathbf{0 . 9 9 2 3}$ & 1.0078 \\
\hline Amphitheatre Seating & 1562 & 6.4 & 0.17 & 0.0441 & $\mathbf{1 . 0 0 1 4}$ & 0.9986 \\
\hline Ceramics & 1732 & 7.1 & 0.33 & 0.0497 & $\mathbf{1 . 1 3 0 7}$ & 0.8844 \\
\hline Sky Theatre & 1745 & 7.1 & 0.50 & 0.0502 & $\mathbf{1 . 1 4 0 5}$ & 0.8768 \\
\hline Roof Patio & 1759 & 7.2 & 0.33 & 0.0507 & $\mathbf{1 . 1 5 1 2}$ & 0.8687 \\
\hline Vault Roof & 1799 & 7.3 & 0.50 & 0.0520 & $\mathbf{1 . 1 8 1 6}$ & 0.8463 \\
\hline Amphitheatre Stage & 1859 & 7.6 & 0.20 & 0.0540 & $\mathbf{1 . 2 2 7 2}$ & 0.8148 \\
\hline EC Roof* & 1875 & 7.7 & 0.20 & 0.0545 & 1.2394 & 0.8068 \\
\hline Café & 1912 & 7.8 & 0.20 & 0.0558 & $\mathbf{1 . 2 6 7 5}$ & 0.7889 \\
\hline Music Centre & 1937 & 7.9 & 0.33 & 0.0566 & $\mathbf{1 . 2 8 6 5}$ & 0.7773 \\
\hline Classroom & 1992 & 8.1 & 1.00 & 0.0584 & $\mathbf{1 . 3 2 8 4}$ & 0.7528 \\
\hline Red Room & 2353 & 9.6 & 0.33 & 0.0705 & $\mathbf{1 . 6 0 2 8}$ & 0.6239 \\
\hline Office & 2372 & 9.7 & 0.25 & 0.0712 & $\mathbf{1 . 6 1 7 3}$ & 0.6183 \\
\hline & & & & & & \\
\hline Averages & 1745 & 7.1 & 0.36 & 0.0502 & $\mathbf{1 . 1 4 0 4}$ & 0.9069 \\
\hline
\end{tabular}

*New Social Space Created by Construction

*Existing Social Space Removed by Construction

Figure 8 Phase II RRA Results

The table in fig. 8 shows the recalculated RRA values following Phase II construction, and highlights new spaces created and existing spaces lost. As seen in fig. 8, the new construction would alter very little about the spatial connectivity across the Arcosanti site, with the Vaults and Office remaining most and least spatially connected respectively. The Keystone Courtyard would now be the $3^{\text {rd }}$ most connected social space while the East Crescent Roof's connectivity improves slightly although it is now no longer a social space but an access corridor for the new studio apartments.

$$
\text { PHASE II }
$$

SHORT TERM CONSTRUCTION

ORDERED BY HIGHEST TO LOWEST VN (MOST TO LEAST VISIBILITY OF NATURE)

\begin{tabular}{|c|c|c|c|c|c|c|c|c|c|c|c|c|c|c|}
\hline \multirow{3}{*}{ Social Space } & \multicolumn{7}{|c|}{ Permeability (\%) } & \multirow{2}{*}{\multicolumn{6}{|c|}{ Naturalness of View }} & \multirow{3}{*}{$\begin{array}{l}\text { Visibility of Nature } \\
\text { (VN) Value }\end{array}$} \\
\hline & $\mathrm{N}$ & $\mathrm{E}$ & $\mathrm{S}$ & W & ABOVE & \multirow{2}{*}{$\begin{array}{l}\text { Total } \\
\text { Open }\end{array}$} & \multirow{2}{*}{ Ratio } & & & & & & & \\
\hline & Open & Open & Open & Open & Open & & & $\mathrm{N}$ & $E$ & $S$ & $\mathrm{~W}$ & ABOVE & $T$ & \\
\hline Vault Roof & 100 & 100 & 100 & 100 & 100 & 100 & 1.00 & 0.5 & 0 & 1 & 0 & 1 & 0.5 & 0.50 \\
\hline Sky Theatre & 82 & 100 & 100 & 100 & 100 & 96.4 & 0.96 & 0 & 0 & 1 & 0 & 1 & 0.4 & 0.39 \\
\hline Roof Patio & 95 & 82 & 91 & 90 & 100 & 91.6 & 0.92 & 0.5 & 0 & 0 & 0 & 1 & 0.3 & 0.27 \\
\hline Ceramics & 12 & 65 & 100 & 65 & 74 & 63.2 & 0.63 & 0 & 0 & 0.25 & 0 & 1 & 0.25 & 0.16 \\
\hline Vaults & 42 & 30 & 100 & 33 & 32 & 47.4 & 0.47 & 0 & 0 & \begin{tabular}{|l|}
0.5 \\
\end{tabular} & 0 & 1 & 0.3 & 0.14 \\
\hline Café & 0 & 25 & 27 & 33 & 16 & 20.2 & 0.20 & 0 & 0.25 & 0.75 & 0.75 & 1 & 0.55 & 0.11 \\
\hline Red Room & 15 & 19 & 28 & 12 & 6 & 16 & 0.16 & 0.5 & 0.5 & 0.75 & 0 & 0.5 & 0.45 & 0.07 \\
\hline Office & 0 & 33 & 26 & 0 & 9 & 13.6 & 0.14 & 0 & 0.5 & 0.75 & 0 & 1 & 0.45 & 0.06 \\
\hline Music Centre & 53 & 0 & 64 & 0 & 0 & 23.4 & 0.23 & 0 & 0 & 0.75 & 0 & 0 & 0.15 & 0.04 \\
\hline Classroom & 0 & 30 & 0 & 29 & 0 & 11.8 & 0.12 & 0 & 0.75 & 0 & 0 & 0 & 0.15 & 0.02 \\
\hline Amphitheatre Seating & 100 & 100 & 100 & 100 & 0 & 80 & 0.80 & 0 & 0 & 0 & 0 & 0 & 0 & 0.00 \\
\hline Amphitheatre Stage & 100 & 46 & 42 & 43 & 0 & 46.2 & 0.46 & 0 & 0 & 0 & 0 & 0 & 0 & 0.00 \\
\hline Community Room & 0 & 54 & 0 & 0 & 0 & 10.8 & 0.11 & 0 & 0 & 0 & 0 & 0 & 0 & 0.00 \\
\hline EC as Planned & 91 & 79 & 65 & 79 & 31 & 69 & 0.69 & 0 & 0 & 0 & 0 & 0 & 0 & 0.00 \\
\hline Keystone Courtyard & 25 & 0 & 100 & 0 & 0 & 25 & 0.25 & 0 & 0 & 0 & 0 & 0 & 0 & 0.00 \\
\hline Library/Rec Room & 0 & 0 & 0 & 0 & 0 & 0 & 0.00 & 0 & 0 & 0 & 0 & 0 & 0 & 0.00 \\
\hline AVG & 45 & 50 & 57 & 46 & 32 & 46.022 & 0.46 & 0.1 & 0.2 & 0.4 & 0.0 & 0.5 & 0.24 & 0.14 \\
\hline
\end{tabular}


Again, the table in fig. 9 shows the recalculated values and changes to spaces following Phase II construction, this time for the VN values. The VN values for Phase II change much more significantly than the RRA values. The East Crescent Roof was previously the social space with the highest visual connection to Nature; Phase II construction now reduces its VN value from 0.69 to 0.00 , with the Vaults Roof replacing it as the space with the highest VN. Additionally, the construction of a permanent canopy above the Amphitheatre eliminates any visibility of the sky from the Amphitheatre's two social spaces, reducing both their VN values to 0.00 . The Keystone Courtyard was also calculated as having a VN value of 0.00 .

PHASE III

LONG TERM CONSTRUCTION

ORDERED BY LOWEST TO HIGHEST RRA (MOST TO LEAST SPATIALLY CONNECTED

\begin{tabular}{|c|c|c|c|c|c|c|}
\hline Social Space & Total Depth & Mean Depth & Connectivity & RA & RRA & Integration Value \\
\hline Ceramics & 5298 & 6.5 & 0.33 & 0.0136 & 0.5032 & 1.9871 \\
\hline Community Room & 6015 & 7.4 & 0.20 & 0.0158 & 0.5837 & 1.7132 \\
\hline Café & 6074 & 7.5 & 0.20 & 0.0159 & 0.5903 & 1.6940 \\
\hline Vault Roof & 6574 & 8.1 & 0.50 & 0.0175 & 0.6464 & 1.5470 \\
\hline Roof Patio & 7454 & 9.2 & 0.33 & 0.0201 & 0.7452 & 1.3420 \\
\hline Vaults & 7525 & 9.3 & 0.17 & 0.0203 & 0.7531 & 1.3278 \\
\hline Library/Rec Room & 7721 & 9.5 & 0.50 & 0.0209 & 0.7751 & 1.2901 \\
\hline Music Centre & 8341 & 10.3 & 0.33 & 0.0228 & 0.8447 & 1.1839 \\
\hline Amphitheatre Stage & 8796 & 10.8 & 0.20 & 0.0242 & 0.8957 & 1.1164 \\
\hline Sky Theatre & 9029 & 11.1 & 0.50 & 0.0249 & 0.9219 & 1.0847 \\
\hline Amphitheatre Seating & 9134 & 11.2 & 0.17 & 0.0252 & 0.9337 & 1.0710 \\
\hline Keystone Courtyard & 9591 & 11.8 & 0.50 & 0.0266 & 0.9850 & 1.0153 \\
\hline Red Room & 10168 & 12.5 & 0.33 & 0.0283 & 1.0497 & 0.9527 \\
\hline Office & 11026 & 13.6 & 0.25 & 0.0309 & 1.1460 & 0.8726 \\
\hline EC Roof & 11096 & 13.6 & 0.20 & 0.0312 & 1.1538 & 0.8667 \\
\hline Classroom & 11326 & 13.9 & 1.00 & 0.0319 & 1.1796 & 0.8477 \\
\hline Averages & 8448 & 10.4 & 0.36 & 0.0231 & 0.8567 & 1.2445 \\
\hline
\end{tabular}

Figure 10 Phase III RRA Results

The changes in spatial connectivity by Phase III are much more significant than in Phase II; the changes in RRA can be seen in fig. 10. As a whole, the spatial connectivity of the Arcosanti site considerably improves, with the average RRA calculated at 0.8567 , and the most connected space returning an RRA of 0.5032, a value in the range which is described as a very strong connection. The social space which would be most connected in Phase III is Ceramics, while the Classroom becomes the least connected, at 1.1796. The Vaults, previously the most spatially connected space in both Phases I and II, is now approximately mid table with an RRA of 0.7531 . 
PHASE III

LONG TERM CONSTRUCTION

ORDERED BY HIGHEST TO LOWEST VN (MOST TO LEAST VISIBILITY OF NATURE)

\begin{tabular}{|c|c|c|c|c|c|c|c|c|c|c|c|c|c|c|}
\hline \multirow{3}{*}{ Social Space } & \multicolumn{7}{|c|}{ Permeability (\%) } & \multirow{2}{*}{\multicolumn{6}{|c|}{ Naturalness of View }} & \multirow{3}{*}{$\begin{array}{l}\text { Visibility of Nature } \\
\text { (VN) Value }\end{array}$} \\
\hline & \multirow{2}{*}{$\begin{array}{c}\mathrm{N} \\
\text { Open }\end{array}$} & \multirow{2}{*}{$\begin{array}{c}\mathrm{E} \\
\text { Open }\end{array}$} & \multirow{2}{*}{$\begin{array}{c}\text { S } \\
\text { Open }\end{array}$} & \multirow{2}{*}{$\begin{array}{c}\text { W } \\
\text { Open }\end{array}$} & \multirow{2}{*}{\begin{tabular}{c|} 
ABOVE \\
Open
\end{tabular}} & \multirow{2}{*}{$\begin{array}{l}\text { Total } \\
\text { Open }\end{array}$} & \multirow{2}{*}{ Ratio } & & & & & & & \\
\hline & & & & & & & & $\mathrm{N}$ & $\mathrm{E}$ & $\mathrm{S}$ & W & ABOVE & $T$ & \\
\hline Vault Roof & 100 & 100 & 100 & 100 & 100 & 100 & 1.00 & 0.75 & 0 & 0.75 & 0 & 1 & 0.5 & 0.50 \\
\hline Sky Theatre & 82 & 100 & 100 & 100 & 100 & 96.4 & 0.96 & 0 & 0 & 0.75 & 0 & 1 & 0.35 & 0.34 \\
\hline Roof Patio & 95 & 82 & 91 & 90 & 100 & 91.6 & 0.92 & 0.5 & 0 & 0 & 0 & 1 & 0.3 & 0.27 \\
\hline Ceramics & 12 & 65 & 100 & 65 & 74 & 63.2 & 0.63 & 0 & 0 & 0 & 0 & 1 & 0.2 & 0.13 \\
\hline Vaults & 42 & 30 & 100 & 33 & 32 & 47.4 & 0.47 & 0 & 0 & 0 & 0 & 1 & 0.2 & 0.09 \\
\hline Café & 0 & 25 & 27 & 33 & 16 & 20.2 & 0.20 & 0 & 0 & 1 & 0 & 1 & 0.4 & 0.08 \\
\hline Red Room & 15 & 19 & 28 & 12 & 6 & 16 & 0.16 & 0.5 & 0.5 & 0 & 0 & 0.5 & 0.3 & 0.05 \\
\hline Office & 0 & 33 & 26 & 0 & 9 & 13.6 & 0.14 & 0 & 0.5 & 0 & 0 & 1 & 0.3 & 0.04 \\
\hline Classroom & 0 & 30 & 0 & 29 & 0 & 11.8 & 0.12 & 0 & 0.75 & 0 & 0 & 0 & 0.15 & 0.02 \\
\hline Amphitheatre Seating & 100 & 100 & 100 & 100 & 0 & 80 & 0.80 & 0 & 0 & 0 & 0 & 0 & 0 & 0.00 \\
\hline Amphitheatre Stage & 100 & 46 & 42 & 43 & 0 & 46.2 & 0.46 & 0 & 0 & 0 & 0 & 0 & 0 & 0.00 \\
\hline Community Room & 0 & 54 & 0 & 0 & 0 & 10.8 & 0.11 & 0 & 0 & 0 & 0 & 0 & 0 & 0.00 \\
\hline EC Roof & 91 & 79 & 65 & 79 & 31 & 69 & 0.69 & 0 & 0 & 0 & 0 & 0 & 0 & 0.00 \\
\hline \begin{tabular}{|l|} 
Keystone Courtyard \\
\end{tabular} & 25 & 0 & 100 & 0 & 0 & 25 & 0.25 & 0 & 0 & 0 & 0 & 0 & 0 & 0.00 \\
\hline \begin{tabular}{|l|} 
Library/Rec Room \\
\end{tabular} & 0 & 0 & 0 & 0 & 0 & 0 & 0.00 & 0 & 0 & 0 & 0 & 0 & 0 & 0.00 \\
\hline Music Centre & 53 & 0 & 64 & 0 & 0 & 23.4 & 0.23 & 0 & 0 & 0 & 0 & 0 & 0 & 0.00 \\
\hline AVG & 45 & 50 & 57 & 46 & 32 & 46.022 & 0.46 & 0.1 & 0.2 & 0.1 & $\overline{0.0}$ & 0.5 & 0.18 & 0.11 \\
\hline
\end{tabular}

Figure 11 Phase III VN Results

The Phase III construction alters the VN value most significantly for the Music Centre as seen in the results table in fig. 11, completely eliminating any visual relationship with the natural environment, from a VN value of 0.04. The Vaults Roof remains the social space with the highest visibility of Nature with its VN value remaining 0.50 . By Phase III, 7 of the 16 existing social spaces would have no visual relationship with the natural environment at all. The majority of Phase III construction is planned for the South slope of the Arcosanti site, a fact reflected in the significant decrease in average Naturalness of View figures for the South facing views; this average was 0.5 in Phase I and is 0.1 by Phase III.

\section{Projected Changes in Social Interactions}

Using the statistically significant correlations produced by the analysis of Phase I, potential figures for the different types of social interaction for Phases II and III could be projected based on the recalculated space and Nature Syntax values for the 15 existing social spaces. To ensure accurate comparisons, the correlation equations were first applied to the original Space and Nature Syntax values calculated in Phase I to produce hypothetical values for each type of social interaction, thus ensuring the only variants were the new RRA and VN values. The changes in the percentage of each type of social interaction, for each social space and across each Phase, were then calculated showing how alterations in RRA and VN could affect social interaction in the social spaces.

The graph in fig. 12 shows the largest projected decrease in Total People between Phase I and Phase II was seen for the Amphitheatre Seating and Amphitheatre Stage where reductions of $2.4 \%$ and $1.5 \%$ share of activity were projected, respectively. The largest projected increase in Total People was projected for Ceramics, where a $0.8 \%$ increase between Phases II and III offsets a $0.5 \%$ decrease in the previous Phase to produce an overall increase of $0.3 \%$. The Vaults would also see a significant decrease in share of Total People as it becomes a less connected space, with decreases in each Phase resulting in an overall decrease of $1.5 \%$. 


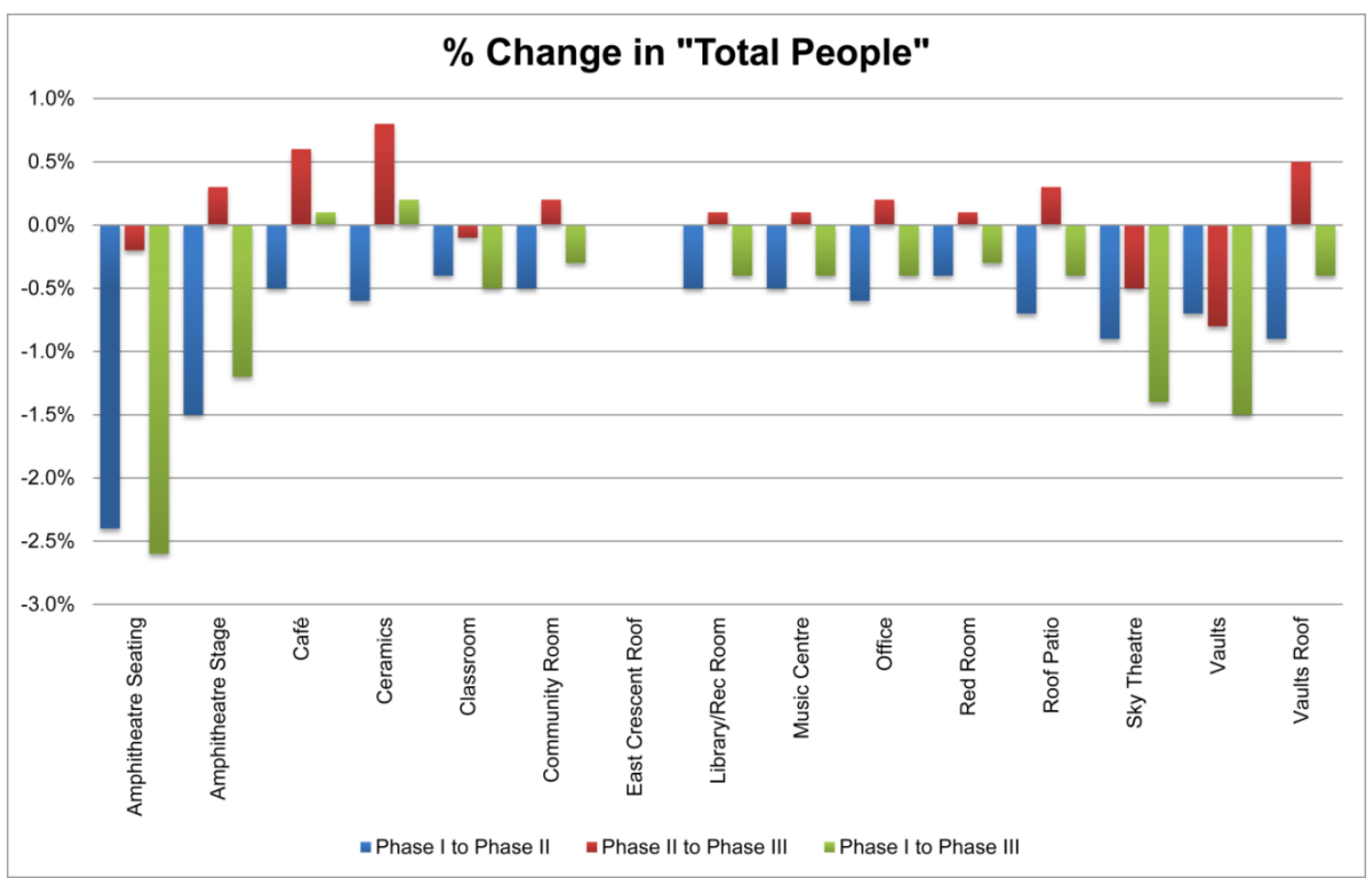

Figure $12 \%$ Change in Total People from Phase I to Phase III

There was a $10 \%$ and 5\% decrease in the percentage of Visual Interaction with the Natural Environment projected in the Amphitheatre Seating and Amphitheatre Stage spaces by Phase II, again due to the removal of any visibility of Nature; fig. 13 shows the projected changes in this activity type. The elimination of the East Crescent Roof as a key space for experiencing a visual relationship with Nature is reflected in the increase in share of Visual Interaction with the Natural Environment for the remaining spaces with a high VN value; the Vaults Roof (+5\%), Sky Theatre (+4.5\%), and Roof Patio (+2.5\%)

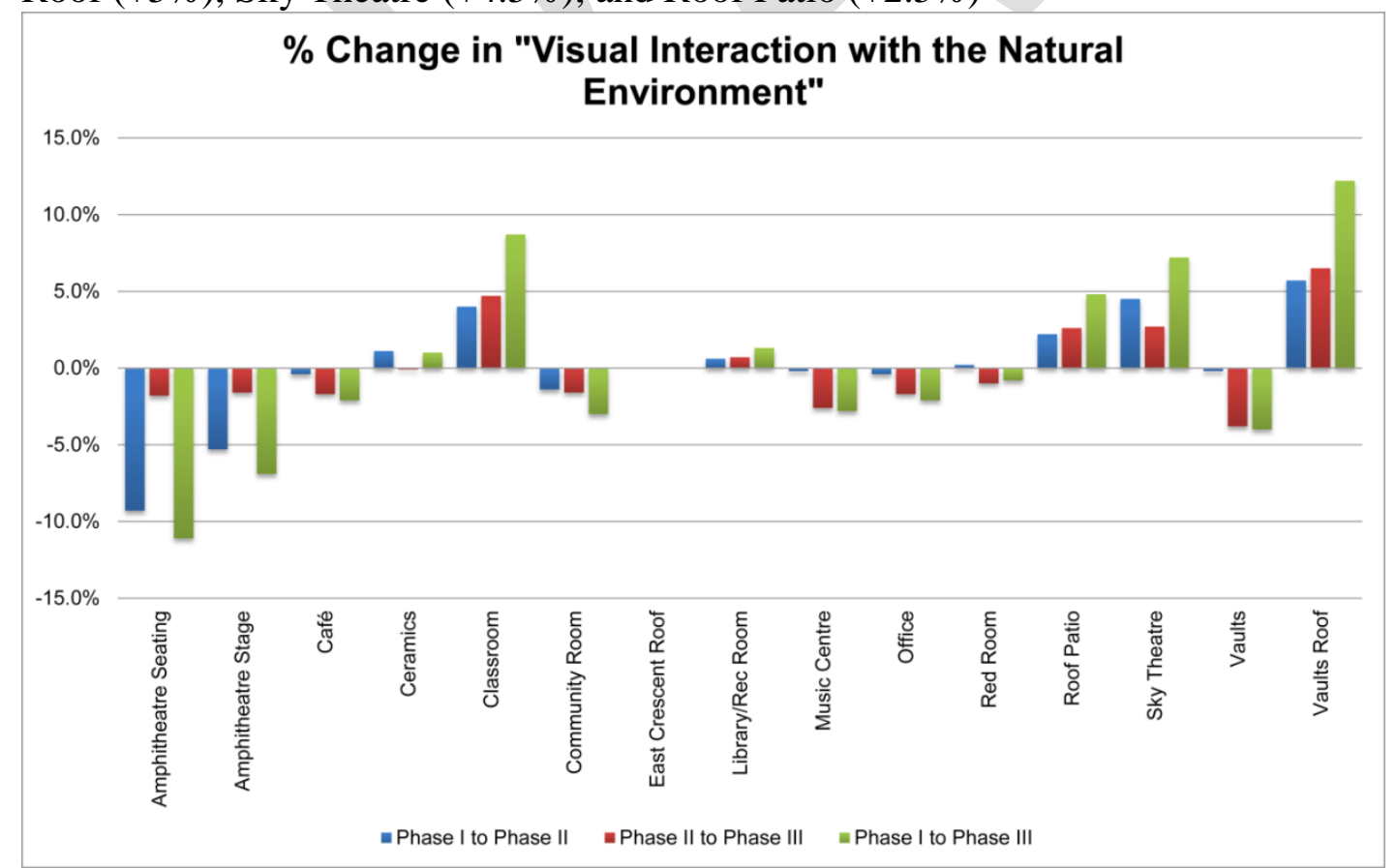

Figure $13 \%$ Change in Visual Interaction with the Natural Environment from Phase I to Phase III

Projected changes for the different types of interaction can also be calculated. Fig. 14 shows how Active and Inactive Use in the 15 social spaces could alter, while fig. 15 shows projected alterations in Planned and Unplanned Use. The correlation between RRA, IV and C, and 
Inactive Use produces a significant change in \% share for Ceramics as it becomes the most spatially connected space, increasing by $4 \%$ between Phase II and III. The Vaults, which had the highest RRA in Phases I and II but fell to mid-table by Phase III, could see its \% share of Inactive Use reduced by 5\% between Phases II and III, and 7\% from Phase I to Phase III.

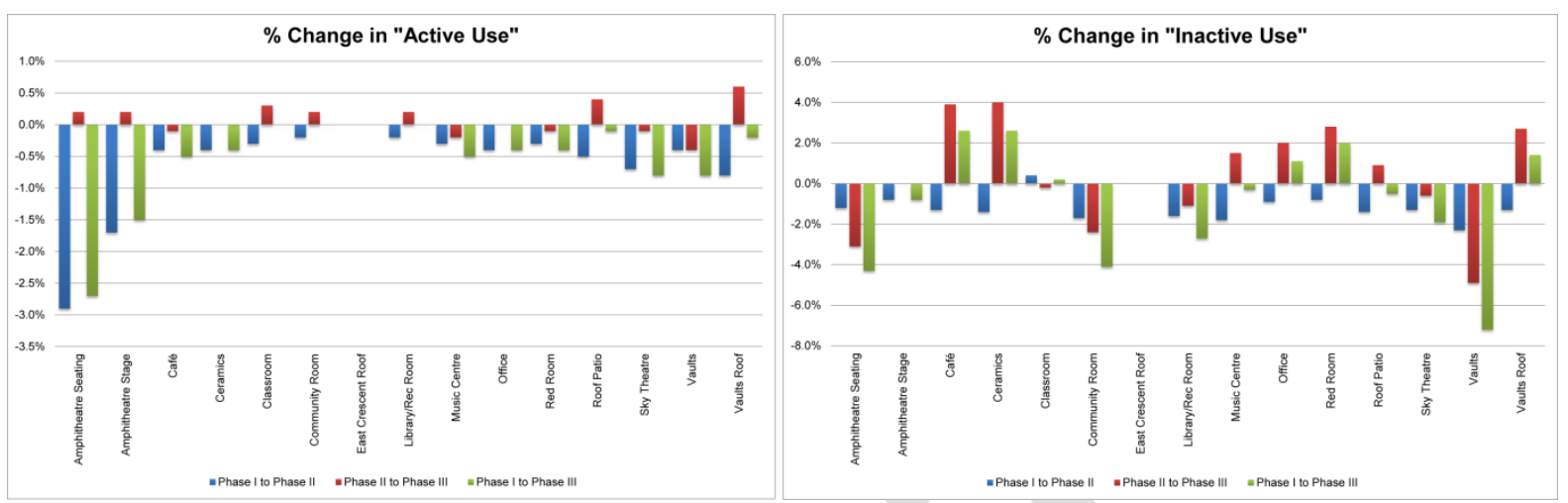

Figure $14 \%$ Change in Active and Inactive Use for Phase I to Phase III

Similar projected changes in \% share could also be seen for Unplanned Use which was correlated significantly with measures of spatial connectivity, where the Vaults could see a reduction of nearly 5\% between Phases I and III as it moves down the spatial connectivity table. Ceramics, although reducing $1 \%$ between Phases I and II, could see an overall increase of 3\% share between Phase I and III as it becomes the most connected space.

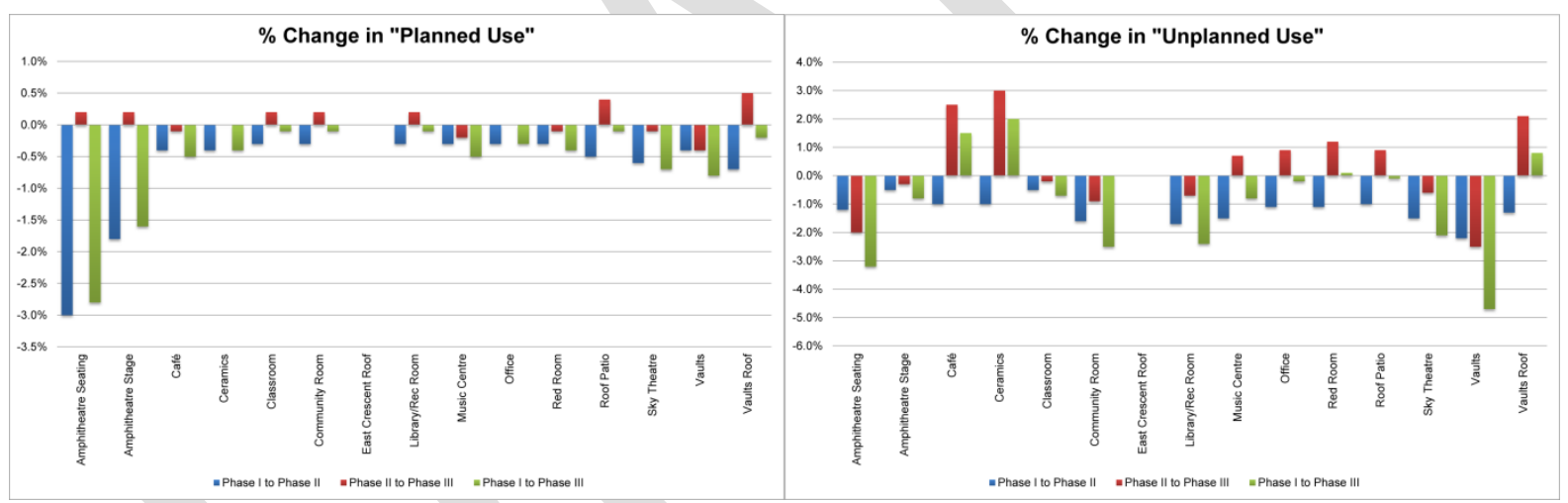

Figure $15 \%$ Change in Planned and Unplanned Use for Phase I to Phase III

Conclusion Discussion of individual spaces at Arcosanti during Phase I seem to support the supposition that visibility of Nature, in addition to spatial connectivity, has a significant role in influencing how social interactions occur, and that the two measures may each inform different types of social interactions. The correlations produced from this data, however, don't support this as strongly; although RRA is significantly correlated with Inactive and Unplanned Use, $\mathrm{VN}$ is correlated only with Visual Interaction with the Natural Environment. Future work will therefore be focussed on an additional visit to the Arcosanti site for the purpose of additional Behavioural Observations, in order to produce more data to further enhance the statistical relationship between spatial connectivity, visibility of Nature and social interactions.

It is important to note and continuously consider that correlation studies do not show cause and effect, merely the existence of a statistically relationship. Thus it cannot be categorically said that, for example, an increase in spatial connectivity definitely causes an increase in Inactive Use; only that a relationship exists between them. It is therefore prudent that the research work continues to progress this consideration by supporting the statistical 
correlations with qualitative evidence that spatial connectivity and visibility of Nature affect how people interact socially in these spaces at Arcosanti. Initial work has been undertaken to develop a method to do this, focussing around questionnaires using established environmental psychology methods of assessing the emotional connection between humans and Nature. This questionnaire could be distributed to residents and visitors to Arcosanti, and trialled alongside further collections of Behavioural Observations on site at Arcosanti.

This paper has briefly demonstrated how the Space/Nature Syntax methodology could be used as an analysis tool when informing future design at the Arcosanti site specifically.

Nevertheless, the process described here is one which is repeatable, and importantly, scalable to both individual buildings or entire sections of cities, therefore even in its current rudimentary state it has potential for application as a design and analysis tool within existing and planned urban social spaces. It must again be stressed that this paper represents a first step towards a fully developed Space/Nature Syntax, and the potentials for future research building on this work cover many academic disciplines. Within the field of architecture and urban design, repeated application of the methodology in different sites, in different cities, will both test and validate the overall applicability of the methodology. Arcosanti is unique in that it is a dense, populated structure closely surrounded by pure untouched Nature; urban settlements across the world do not generally have this clear a boundary between built and natural. However, the method proposed here for assigning Naturalness of View accounts for this; urban greenery in the form of parks, roof top gardens, street lined trees or even green walls could all be categorised and assessed using this method. The academic development of the Space/Nature Syntax is not limited to design based subjects; as mentioned previously, there is a real need for a qualitative evidence to support the quantitative presented here. Therefore there are opportunities for disciplines such as sociology and environmental psychology to build upon the foundations set out within this paper and understand how this statistical approach translates to in-depth human behaviour and thinking. Finally, there could be academic applications of the Space/Nature Syntax in the field of mathematics and statistics; the statistical analysis carried out in this paper is basic, and the data gathered here and in subsequent applications of the method could be explored in greater depth with more advanced statistical knowledge.

The research work on which this paper is based is addressing an intersection between built environment, natural environment, and social interaction which will be all the more relevant as urbanisation continues. Increasingly people are migrating to the city in search of its potential social, economic and cultural benefits, but are sacrificing a generally accepted innate need for connection with Nature and potentially placing themselves at higher risk of the mental health illnesses associated with both city living and withdrawal from Nature. A truly interdisciplinary methodology, the Space/Nature Syntax considers how to maximise the benefits of both Nature and social space within an urban environment, and could prove to be an important research, design and analysis tool for cities in the future.

\section{References}

Adli, M. (2011). "Urban Stress and Mental Health." Cities, Health and Well-being. Hong Kong: London School of Economics.

Anderson, J. R., Hardy, E. E., Roach, J. T. \& Witmer, R. E. (1976). "A Land Use and Land Cover Classification System For Use With Remote Sensor Data." In: UNITED 
STATES DEPARTMENT OF THE INTERIOR (ed.). Washington: United States Government Printing Office.

Bafna, S. (2003). "Space Syntax: A Brief Introduction to Its Logic and Analytical

Techniques". Environment \& Behavior, 35, 17-29.

Benedictus, L. (2014). "Sick cities: why urban living can be bad for your mental health". The Guardian [Online]. Available: http://www.theguardian.com/cities/2014/feb/25/citystress-mental-health-rural-kind [Accessed 24 November 2015].

Berman, M. G., Jonides, J. \& Kaplan, S. (2008). "The cognitive benefits of interacting with nature". Psychology Science, 19, 1207-12.

Berman, M. G., Kross, E., Krpan, K. M., Askren, M. K., Burson, A., Deldin, P. J., Kaplan, S., Sherdell, L., Gotlib, I. H. \& Jonides, J. (2012). "Interacting with nature improves cognition and affect for individuals with depression". J Affect Disord, 140, 300-5.

Brown, T. \& Bell, M. (2007). "Off the couch and on the move: global public health and the medicalisation of nature". Social Science and Medicine, 64, 1343-54.

Campos, M. B. d. A. \& Fong, P. S. P. (2003). "A proposed methodology to normalise total depth values when applying the visibility graph analysis." 4th International Space Syntax Symposium. London.

Cervinka, R., Roderer, K. \& Hefler, E. (2012). "Are nature lovers happy? On various indicators of well-being and connectedness with nature". Journal of Health Psychology, 17, 379-88.

Costa, M. (2011). "Territorial Behavior in Public Settings". Environment and Behavior, 44, 713-721.

Gehl, J. (1987). "Life between buildings : using public space", Copenhagen : Danish Architectural Press.

Gehl, J. (2010). "Cities for people", Washington : Island Press.

Gehl, J. (2011). "'Three Types of Outdoor Activities," "Life Between Buildings," and "Outdoor Activities and the Quality of Outdoor Space""'. In: LEGATES, R. T. \& STOUT, F. (eds.) The City Reader. 5th ed. New York: Routledge.

Gehl, J., Kaefer, L. J. \& Reigstad, S. (2006). "Close encounters with buildings". URBAN DESIGN International, 11, 29-47.

Goličnik, B. \& Ward Thompson, C. (2010). "Emerging relationships between design and use of urban park spaces". Landscape and Urban Planning, 94, 38-53.

Grierson, D. (2003). "Arcology and Arcosanti: Towards a Sustainable Built Environment". Electronic Green Journal, 1.

Grinde, B. \& Patil, G. G. (2009). "Biophilia: does visual contact with nature impact on health and well-being?". International Journal of Environmental Research and Public Health, 6, 2332-43.

Hillier, B. (1999). "The hidden geometry of deformed grids: or, why space syntax works, when it looks as though it shouldn't". Environment and Planning B: Planning and Design, 26, 169-191.

Hillier, B. (2007). "Space is the Machine." Space Syntax at University College London.

Hillier, B. \& Hanson, J. (1984). "The social logic of space", Cambridge, London, Cambridge University Press.

Hillier, B., Leaman, A. \& Bedford, M. (1976). "Space Syntax". Environment and Planning B: Planning and Design, 3, 147-185.

Jeong, S. K. \& Ban, Y. U. (2011). "Computational algorithms to evaluate design solutions using Space Syntax". Computer-Aided Design, 43, 664-676.

Keniger, L. E., Gaston, K. J., Irvine, K. N. \& Fuller, R. A. (2013). "What are the benefits of interacting with nature?". International Journal of Environmental Research and Public Health, 10, 913-35. 
Klarqvist, B. (1993). "A Space Syntax Glossary". Nordic Journal of Architectural Research, 2, 11-12.

Liu, J. H. \& Sibley, C. G. (2004). "Attitudes and behavior in social space: Public good interventions based on shared representations and environmental influences". Journal of Environmental Psychology, 24, 373-384.

Logan, A. C. \& Selhub, E. M. (2012). "Vis Medicatrix naturae: does nature "minister to the mind"?". Biopsychosoc Med, 6, 11.

MacKerron, G. \& Mourato, S. (2013). "Happiness is greater in natural environments". Global Environmental Change, 23, 992-1000.

Moirongo, B. O. (2002). "Urban public space patterns: human distribution and the design of sustainable city centres with reference to Nairobi CBD". URBAN DESIGN International, 7, 205-216.

Munro, K. \& Grierson, D. (2016). "Towards a Space/Nature Syntax: the social importance of proximity to nature, as experienced at Arcosanti, Arizona, USA." Open House International.

Raanaas, R. K., Patil, G. G. \& Hartig, T. (2012). "Health benefits of a view of nature through the window: a quasi-experimental study of patients in a residential rehabilitation center". Clin Rehabil, 26, 21-32.

Sengupta, P. \& Benjamin, A. I. (2015). "Prevalence of depression and associate risk factors among the elderly in urban and rural field practice areas of a tiertary care institution in Lundhiana". Indian Journal of Public Health, 59, 3-8.

Simpson, P. (2011). "Street Performance and the City: Public Space, Sociality, and Intervening in the Everyday". Space and Culture, 14, 415-430.

Soleri, P. (1969). "Arcology : the city in the image of man", Cambridge, Mass. : MIT Press.

Soleri, P. (1993). "Arcosanti : an urban laboratory?", Mayer, AZ : Cosanti Press.

Soleri, P., Kim, Y., Anderson, C., Nordfors, A., Riley, S. \& Tamura, T. (2011). "Lean Linear City: Arterial Arcology", Mayer, AZ, Cosanti Press.

Srivastava, K. (2009). "Urbanization and mental health". Ind Psychiatry J, 18, 75-6.

Thwaites, K. (2007). "Urban sustainability through environmental design : approaches to time, people, and place responsive urban spaces", New York : Routledge.

US Department of the Interior \& US Geological Survey. (2015). "National Land Cover Database 2006 (NLCD 2006) [Online]". Available: http://www.mrlc.gov/nlcd2006.php [Accessed 12 December 2014].

W.H.O. (2012). "Urban Population Growth [Online]". Available: http://www.who.int/gho/urban_health/situation_trends/urban_population_growth_text len/ [Accessed 28th September 2013].

Ward Thompson, C. (2011). "Linking landscape and health: The recurring theme". Landscape and Urban Planning, 99, 187-195.

Wilson, E. O. (1984). "Biophilia", Harvard University Press.

Zhang, W. \& Lawson, G. (2009). "Meeting and greeting: Activities in public outdoor spaces outside high-density urban residential communities". URBAN DESIGN International, $14,207-214$.

\section{Biographical Note}

Karen Munro is a PhD researcher in the Department of Architecture at the University of Strathclyde, Glasgow, Scotland. She graduated with a BSc (Hons) in Architectural Studies in 2010, and MRes Building Design and Management for Sustainability in 2012, both also from the University of Strathclyde. Since 2013 she has worked alongside Dr David Grierson in 
developing the collaborative partnership between the University of Strathclyde and the Cosanti Foundation in Arizona, USA, through both her $\mathrm{PhD}$ and the establishment of a MSc Sustainable Engineering: Architecture and Ecology degree which is delivered jointly between the University and the Cosanti Foundation, in Glasgow and Arizona. Her main research interest is sustainable development in cities, particularly around the study of public space, environmental-related behaviour, and connections between built and natural environments. Throughout her time at the University of Strathclyde, she has assisted in conference and event organisation, been elected student representative, and contributed to the delivery and assessment of Sustainability classes. She has also worked with staff and students from across the Architecture department on an application to obtain the Athena Swan Bronze Award.

Dr David Grierson is Deputy Head of the Department of Architecture at the University of Strathclyde Glasgow. He also chairs Strathclyde's Graduate School of Engineering, and has directed the Faculty-wide postgraduate programme in Sustainable Engineering since 2004. $\mathrm{He}$ is a registered architect (ARB) and a Fellow of the Higher Education Academy (FHEAD). Dr Grierson has been external examiner at University College London (UCL) and holds current examiner appointments at Sheffield Hallam University, in England, and Queen's University Belfast in Northern Ireland. Dr Grierson's research interests include sustainable architecture and ecological design. His subject expertise in sustainability has led to a large number of peer-reviewed international publications and to his recent appointments as visiting professor at Universities in Doha in Qatar, and Rome and Florence in Italy. In 2013 Dr Grierson was appointed as the first visiting professor at Arcosanti in Arizona, USA, and joined the Steering Committee of the Cosanti Foundation, USA, overseeing the strategic plan for the development of an experimental prototype sustainable city in the Arizona desert in the United States.

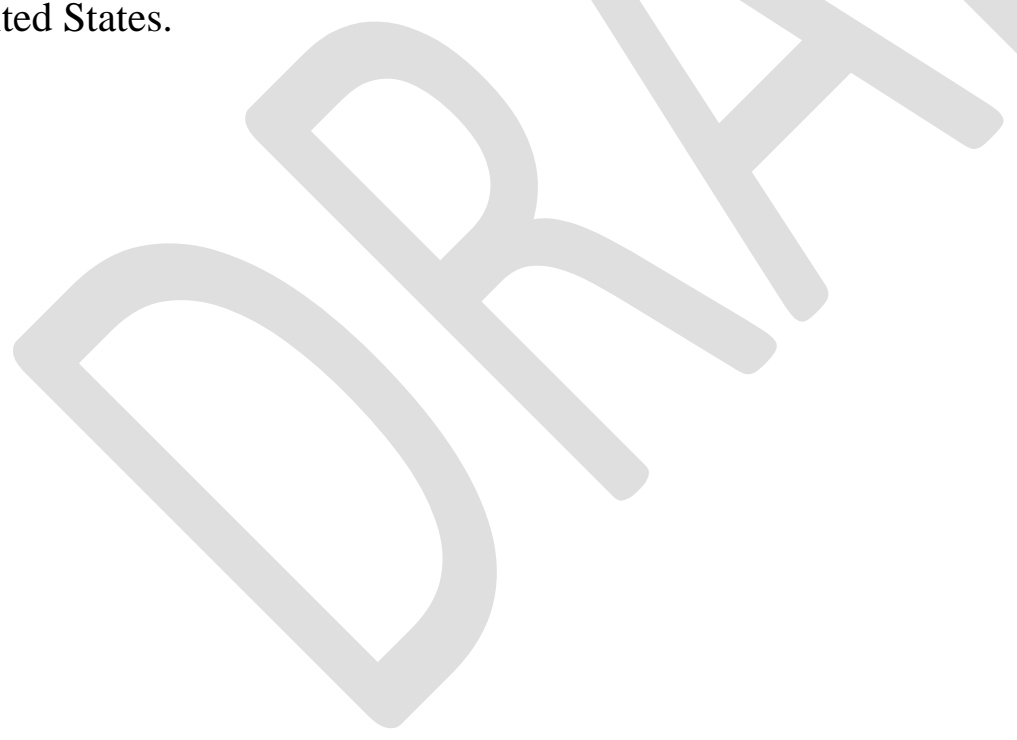

